Article

\title{
Emotional Labor and Burnout of Public Health Nurses during the COVID-19 Pandemic: Mediating Effects of Perceived Health Status and Perceived Organizational Support
}

\author{
Mi-Na Kim ${ }^{1}$, Yang-Sook Yoo ${ }^{1, *(1)}$, Ok-Hee Cho ${ }^{2}$ and Kyung-Hye Hwang ${ }^{3}$ \\ 1 College of Nursing, The Catholic University of Korea, 222 Banpo-daero, Seoul 06591, Korea; \\ mina0650@hanmail.net \\ 2 Department of Nursing, College of Nursing and Health, Kongju National University, 56 Gongju-deahak-ro, \\ Gongju-si 32588, Korea; ohcho@kongju.ac.kr \\ 3 Department of Nursing, Suwon Science College, 288 Seja-ro, Hwaseong-si 18516, Korea; hkh@ssc.ac.kr \\ * Correspondence: ysyoo@catholic.ac.kr
}

check for updates

Citation: Kim, M.-N.; Yoo, Y.-S.; Cho, O.-H.; Hwang, K.-H. Emotional Labor and Burnout of Public Health Nurses during the COVID-19 Pandemic: Mediating Effects of Perceived Health Status and Perceived Organizational Support. Int. J. Environ. Res. Public Health 2022 19, 549. https://doi.org/10.3390/ ijerph19010549

Academic Editor: Paul B. Tchounwou

Received: 16 November 2021

Accepted: 2 January 2022

Published: 4 January 2022

Publisher's Note: MDPI stays neutral with regard to jurisdictional claims in published maps and institutional affiliations.

Copyright: () 2022 by the authors Licensee MDPI, Basel, Switzerland. This article is an open access article distributed under the terms and conditions of the Creative Commons Attribution (CC BY) license (https:// creativecommons.org/licenses/by/ $4.0 /)$.

\begin{abstract}
The purpose of this study was to identify the mediating effects of perceived health status (PHS) and perceived organizational support (POS) in the association between emotional labor and burnout in public health nurses (PHNs). The participants were 207 PHNs convenience sampled from 30 public health centers and offices in Jeju, Korea. Data regarding emotional labor, PHS, POS, and burnout were collected between February and March 2021 using a structured questionnaire. Collected data were analyzed by Pearson's correlation coefficient and multiple regression analysis. Burnout of PHNs was positively correlated with emotional labor $(\mathrm{r}=0.64, p<0.001)$ and negatively correlated with PHS $(\mathrm{r}=-0.51, p<0.001)$ and POS $(\mathrm{r}=-0.51, p<0.001)$. In the association between emotional labor and burnout, PHS $(\mathrm{B}=-1.36, p<0.001)$ and POS $(\mathrm{B}=-0.42, p=0.001)$ had a partial mediating effect. Reduction of burnout among PHNs requires not only effective management of emotional labor but also personal and organizational efforts to improve PHS and POS.
\end{abstract}

Keywords: nurses; public health; emotions; burnout; health status; social support

\section{Introduction \\ 1.1. Necessity of Study}

The entire world is facing an unprecedented event due to the sudden COVID-19 pandemic. As the pandemic has lingered on and expanded to communities, the public health policies of the government and health authorities are changing constantly. Public health centers are basic but core institutions within the public healthcare network, while public health nurses (PHNs) provide primary healthcare services to community residents for disease prevention and health promotion [1]. However, during the global pandemic crisis, PHNs have faced a sharp increase in their workload for infection control and dealing with complaints [2], screening [3], as well as added work for cohort isolation, contact tracing, and self-isolation training; vaccination; and follow-up actions for adverse symptoms after vaccination [4]. Accordingly, PHNs are suffering from physical and mental fatigue and burnout due to increased workload, emergency shifts, task shifting, and role changes caused by the pandemic [5]. An online survey conducted in the US during August-September 2020 reported that $66.2 \%$ of 225 public health workers experienced burnout [6]. The number of Korean PHNs switching jobs during the calendar year 2020 increased by approximately 1.5 times compared to the previous three years [7].

Burnout is a negative psychological experience from repeated exposure to stressors, and for nurses, it is caused or worsened by emotional frustration, lack of competency [8], feeling pushed beyond training [9], emotional labor [10], and lack of organizational support [11]. A previous study that conducted a meta-analysis on prospective studies [12] 
reported that job burnout is associated with musculoskeletal symptoms, chronic disease, and cerebrovascular disease, and it may cause insomnia, depression, and lower job satisfaction. Burnout of PHNs during the COVID-19 pandemic could not only cause personal health problems [6] but also have a negative effect such as loss of work performance or decline in the quality of health care services [13,14]. As the COVID-19 pandemic has continued to linger into October 2021, identification of burnout among PHNs and associated factors could help enhance the professional quality of life of PHNs and could serve as important data for developing strategies to maintain the public health crisis management system.

Emotional labor is a stressor that leads to burnout [15], most PHNs live in the community where they work and provide public health nursing through direct interactions with the residents, and thus, they are even more vulnerable to stress and burnout caused by emotional labor [14,16]. Many previous studies have reported that excessive emotional labor can cause mental health problems, such as emotional distress [17], depression, anxiety, and frustration, as well as musculoskeletal symptoms, pain, menstrual irregularity [10], weakness, cardiovascular disease [18], and other physical health problems [19], while also causing a decrease in perceived health status (PHS). In a study that was conducted during the COVID-19 pandemic [5], PHNs felt physical and emotional fatigue and perceived their health status to be poorer due to face-to-face work for contact tracing, COVID-19-related tests, and self-isolation.

Higher emotional labor among nurses resulted in decreased job satisfaction [20], presenteeism, perceived organization support (POS) [21], and professional quality of life [16], which suggested that emotional labor negatively affects not only the individual but also the organization. POS refers to a set of beliefs that members have about organizational support, which includes such as organizational reward, fairness, favorable job conditions, working environments, closeness with colleagues, and positive atmosphere [22,23]. High POS reduces work stress, enhances resilience [24], increases job satisfaction and organizational commitment [25], and reduces burnout [11] among nurses. Other previous studies also reported that emotional labor [26] and POS [27] are factors affecting burnout of health care provider [28].

While there have been studies on emotional labor and burnout experienced by nurses under the recent COVID-19 pandemic, there is a lack of studies investigating the mediating factors in the association between emotional labor and burnout. Some previous studies on burnout among PHNs measured burnout status with just a single question; as a result, there is only limited information about burnout and there are difficulties in identifying its association with other factors. Accordingly, this study aimed to present basic data for developing burnout prevention programs by investigating the associations between emotional labor, PHS, POS, and burnout experienced by PHNs during the COVID-19 pandemic, which has over two years.

\subsection{Purpose}

The purpose of this study was to identify the mediating effects of PHS and POS in the association between emotional labor and burnout in PHNs. The specific purposes were: (1) to identify COVID-19 pandemic-related psychological burdens experienced by PHNs;

(2) to identify the mediating effects of PHS and POS in the association between emotional labor and burnout in PHNs.

\section{Methods}

\subsection{Study Design}

This study was a cross-sectional descriptive survey using a structured questionnaire to investigate the associations between emotional labor, PHS, POS, and burnout perceived by PNHs during the COVID-19 pandemic. 


\subsection{Participants and Data Collection}

The contents and methods of the study were approved by the Institutional Review Board of the university affiliated with the authors prior to the start of the study. Data were collected between February and March 2021. The participants were convenience sampled from PHNs with at least six months of work experience in public health centers and offices, graduated from 3-year or 4-year university in Jeju, Korea. At the time of the survey, there were six public health centers and 48 public health offices in Jeju Island, with 336 PHNs working in those institutions. Of these, permission for data collection was obtained from the heads of six public health centers and 24 public health offices. A single researcher personally visited the participants while following the government infectious disease control guidelines. The single researcher explained the overall content of the study (objective, survey method, questionnaire, to the candidates who satisfy the inclusion criteria by one to one. Ethical considerations were explained to the participants, that the collected data would only be used for the study and that there would be no disadvantages if they were to withdraw from the study. In addition, questionnaires were distributed to those who submitted a signed consent from one to one. The questionnaire, which required approximately 20 min to complete, was filled out by each participant and retrieved immediately upon completion on the spot. Each participant was given a small token of appreciation (approximately USD 10 in value). When the sample size needed for regression analysis was calculated using the $\mathrm{G}^{*}$ Power 3.1.2 program (moderate effect size of 0.15 , significance level of 0.05 , and statistical power of $95 \%$ ), the minimum sample size was 172. Considering the drop-out rate, a total of 210 candidates were recruited. After excluding three candidates with too many missing responses, data from a total of 207 participants were used in the final analysis.

The mean age of the participants was 37.4 years (range: $22-59$ years), with $36.7 \%$ of the participants aged $<30$ years. Of the participants, $96.1 \%$ were females, $55.1 \%$ had a spouse, and $46.9 \%$ were full-time workers. The percentage of participants with clinical nursing experience of $\geq 5$ years was $51.2 \%$, and the percentage of those with public health center work experience of $\geq 3$ years was $56.5 \%$. The percentage of participants who listed "visiting nursing" and "infectious disease control" as their main responsibility was $40.6 \%$ and $31.9 \%$, respectively. The percentage of participants with $<6$ work hours per day for the past one month was $46.4 \% ; 50.7 \%$ of participants had $\geq 4$ h of COVID-19-related work experience; $63.8 \%$ had $\geq 2$ h of COVID-19-related complaint response times; $59.9 \%$ had $\geq 2 \mathrm{~h}$ of overtime work (Table 1 ).

\subsection{Measures}

\subsubsection{General Characteristics of Participants}

The general characteristics of participants surveyed included gender, age, spouse status, type of work institution (public health center/office), employment type (full time, part-time, and public service), clinical nursing experience (in years), work experience in public health center (in years), responsibilities (multiple responses possible), work hours per day for past one month, COVID-19-related work hours, COVID-19-related complaint response time, and overtime work.

\subsubsection{COVID-19 Pandemic-Related Psychological Burden}

To identify psychological burden, the question, "how much psychological burden did you feel due to the COVID-19 pandemic" in past one month was asked for five items. Each item was graded on a scale of "not difficult at all" (1 point) to "very difficult" (10 points), with higher total scores indicating higher psychological burden. The validity of the tool was assessed by two nursing professors and three PHNs with more than 10 years of experience, and 5 items with a content validity index (CVI) of 0.8 or higher were selected. The overall CVI was 0.9. 
Table 1. Burnout according to general characteristics of participants.

\begin{tabular}{|c|c|c|c|c|}
\hline \multirow[b]{2}{*}{ Characteristics } & \multirow[b]{2}{*}{ Categories } & \multirow[b]{2}{*}{$\mathbf{N}(\%)$ or $\mathbf{M} \pm \mathbf{S D}$} & \multicolumn{2}{|c|}{ Burnout } \\
\hline & & & $\mathbf{M} \pm \mathbf{S D}$ & $\begin{array}{c}\text { t or } F(p) \\
\text { Scheffe Test }\end{array}$ \\
\hline \multirow[t]{5}{*}{ Age } & & $37.4 \pm 11.0(22-59)$ & & \\
\hline & $<30$ & $76(36.7)$ & $66.12 \pm 14.36$ & $5.44(0.001)$ \\
\hline & $30 \sim 39$ & $51(24.6)$ & $65.12 \pm 14.29$ & $a, b, c>d$ \\
\hline & $40 \sim 49$ & $38(18.4)$ & $62.82 \pm 12.10$ & \\
\hline & $\geq 50$ & $42(20.3)$ & $56.36 \pm 9.67$ & \\
\hline \multirow[t]{2}{*}{ Gender } & Female & $199(96.1)$ & $63.79 \pm 13.18$ & $-2.71(0.007)$ \\
\hline & male & $8(3.9)$ & $50.75 \pm 17.11$ & \\
\hline \multirow[t]{2}{*}{ Spouse } & No & $93(44.9)$ & $65.27 \pm 13.71$ & $1.92(0.057)$ \\
\hline & Yes & $114(55.1)$ & $61.67 \pm 13.23$ & \\
\hline \multirow[t]{2}{*}{ Working institution } & $\begin{array}{l}\text { Public health care } \\
\text { center }\end{array}$ & $181(87.4)$ & $63.79 \pm 13.59$ & $1.42(0.157)$ \\
\hline & Public health office & $26(12.6)$ & $59.77 \pm 12.81$ & \\
\hline \multirow{2}{*}{ Employment type } & Regular worker & $97(46.9)$ & $64.84 \pm 11.50$ & $3.49(<0.001)$ \\
\hline & Irregular workers & $110(53.1)$ & $59.19 \pm 11.70$ & \\
\hline \multirow[t]{2}{*}{ Total nurse career (years) } & $<5$ & $101(48.8)$ & $64.18 \pm 13.90$ & $1.11(0.600)$ \\
\hline & $\geq 5$ & $106(51.2)$ & $62.43 \pm 13.19$ & \\
\hline \multirow{2}{*}{$\begin{array}{l}\text { Career of employment in healthcare center } \\
\text { (year) }\end{array}$} & $<3$ & $90(43.5)$ & $65.01 \pm 14.01$ & $1.62(0.108)$ \\
\hline & $\geq 3$ & $117(56.5)$ & $61.96 \pm 13.06$ & \\
\hline \multirow[t]{9}{*}{ Responsibilities * } & Visiting nursing & $84(40.6)$ & & \\
\hline & $\begin{array}{l}\text { Infectious disease } \\
\text { control }\end{array}$ & $66(31.9)$ & & \\
\hline & Health promotion & $34(16.4)$ & & \\
\hline & Vaccination & $31(15.0)$ & & \\
\hline & $\begin{array}{l}\text { Health } \\
\text { administration }\end{array}$ & $26(12.6)$ & & \\
\hline & $\begin{array}{l}\text { Medical } \\
\text { management }\end{array}$ & $7(3.4)$ & & \\
\hline & Mental health & $12(5.8)$ & & \\
\hline & $\begin{array}{l}\text { Maternal and child } \\
\text { health }\end{array}$ & $17(8.2)$ & & \\
\hline & Others & $37(17.9)$ & & \\
\hline \multirow[t]{3}{*}{ Responsible business hours, Median (range) } & & $5.94 \pm 3.01(0-15)$ & & \\
\hline & $<6$ & $96(46.4)$ & $65.25 \pm 11.73$ & $1.99(0.048)$ \\
\hline & $\geq 6$ & $111(53.6)$ & $61.59 \pm 14.76$ & \\
\hline \multicolumn{2}{|c|}{ COVID-19 related business hours, Median (range) } & $4(0-32)$ & & \\
\hline & $<4$ & $102(48.3)$ & $60.07 \pm 12.14$ & $-3.46(<0.001)$ \\
\hline & $\geq 4$ & $105(50.7)$ & $66.14 \pm 14.13$ & \\
\hline \multicolumn{2}{|c|}{ COVID-19 related complaints response time, Median (range) } & $2(0-55)$ & & \\
\hline & $<2$ & $75(36.2)$ & $58.31 \pm 14.17$ & $-4.14(<0.001)$ \\
\hline & $\geq 2$ & $132(63.8)$ & $66.11 \pm 12.34$ & \\
\hline \multirow[t]{3}{*}{ Overtimes } & & $2(0-24)$ & & \\
\hline & $<2$ & $83(40.1)$ & $58.99 \pm 13.88$ & $-3.86(<0.001)$ \\
\hline & $\geq 2$ & 124 (59.9) & $66.16 \pm 12.55$ & \\
\hline
\end{tabular}

${ }^{*}$ Multiple response.

\subsubsection{Burnout}

Burnout was measured using the Korean version of the tool developed by Pines et al. [29]. This tool consists of a total of 21 items, including physical burnout (7 items), emotional burnout (7 items), and mental exhaustion (7 items). Each item is graded on a 5 -point Likert scale (not at all $=1$ to always so $=5$ ), with higher total scores indicating a higher level of burnout. In this study, the reliability of the tool was Cronbach's $\alpha=0.92$. 


\subsubsection{Emotional Labor}

Emotional labor was measured using the Korean version of the tool developed by Morris and Feldman [30]. This tool consists of a total of 9 items, including frequency of emotional labor (3 items), attention level of emotional expression ( 3 items), and emotional dissonance ( 3 items). Each item is graded on a 5-point Likert scale (Not at all = 1 to Very much so $=5$ ), with higher total scores indicating higher emotional labor intensity. In this study, the reliability of the tool was Cronbach's $\alpha=0.88$.

\subsubsection{PHS}

PHS was measured using the Korean version of the tool developed by Speake et al. [31]. This tool consists of a total of 3 items: current overall health status, health status compared with peers, and health status satisfaction compared with one years ago. Each item is graded on a 5 -point Likert scale (Not at all $=1$ to Very much so $=5$ ), with higher total scores indicating better PHS. In this study, the reliability of the tool was Cronbach's $\alpha=0.89$.

\subsubsection{POS}

POS was measured using the Korean version of the tool developed by Eisenberger and Huntington [22]. This tool consists of a total of 8 items, including items such as 'our organization values my contribution'. Each item is graded on a 7-point Likert scale (Not at all $=1$ to Very much so $=7$ ), with higher total scores indicating higher POS. In this study, the reliability of the tool was Cronbach's $\alpha=0.88$.

\subsection{Data Analysis}

Collected data were analyzed using SAS 9.4 program. The general characteristics of participants, emotional labor, PHS, POS, and burnout were analyzed using descriptive statistics. Correlations were verified by Pearson's correlation coefficients. To verify the mediating effects of PHS and POS in the association between emotional labor and burnout, PROCESS macro-SPSS/WIN 3.3 program was used to analyze by a parallel multiple mediator model [32] while bootstrapping was used for inference of indirect effect. Emotional labor was inputted as the independent variable; burnout as the dependent variable; PHS and POS as mediating variables. Analysis was performed by inputting four (parallel multiple mediator model) as the model number, 95\% confidence interval (CI), and 10,000 as the bootstrap sample size. Before testing the mediating effects, multicollinearity between independent variables and autocorrelation between dependent variables were checked. The suitability of the regression model was checked by a normal distribution (Kolmogorov-Smirnov's) and homoscedasticity (Breusch-Pagan's) using residual analysis.

\section{Results}

\subsection{Psychological Burden, Burnout, and Related Factors}

The psychological burden due to the COVID-19 pandemic appeared in the order of "Being stricter on one's self than as required by the government with respect to social distancing and restrictions on personal life" (7.36 out of 10 points), "overload of various work assigned additionally because of being a nurse" (7.09 points), and "social expectations about sacrifice as a public servant and expectation of kind response" (6.84 points). The mean score of emotional labor was 31.55 out of 45 points, the mean score of PHS was 9.09 out of 15 points, the mean score of POS was 32.82 out of 56 points, and the mean score of burnout was 63.29 out of 105 points (Table 2). 
Table 2. Psychological burden, burnout, emotional labor, perceived health status, perceived organizational support.

\begin{tabular}{|c|c|c|}
\hline Variables & $\mathbf{M} \pm \mathbf{S D}$ & Min-Max \\
\hline \multicolumn{3}{|l|}{ COVID-19 pandemic related to psychological burden } \\
\hline $\begin{array}{l}\text { Being stricter on one's self than as required by the government with respect to social distancing } \\
\text { and restrictions on personal life }\end{array}$ & $7.36 \pm 2.37$ & $0-10$ \\
\hline Overload of various work assigned additionally because of being a nurse & $7.09 \pm 2.60$ & $0-10$ \\
\hline Social expectations about sacrifice as a public servant and expectation of kind response & $6.84 \pm 2.62$ & $0-10$ \\
\hline Verbal and physical abuse from complaints & $6.06 \pm 2.81$ & $0-10$ \\
\hline Daily life of family members being restricted due to me & $6.65 \pm 2.71$ & $0-10$ \\
\hline Emotional labor & $31.55 \pm 5.68$ & $16-45$ \\
\hline Perceived health status & $9.09 \pm 2.35$ & $3-15$ \\
\hline Perceived organizational support & $32.82 \pm 7.33$ & $8-55$ \\
\hline Burnout & $63.29 \pm 13.53$ & $31-97$ \\
\hline
\end{tabular}

\subsection{Correlations between Burnout and Related Factors}

Burnout was positively correlated with emotional labor $(\mathrm{r}=0.64, p<0.001)$ and negatively correlated with PHS ( $\mathrm{r}=-0.51, p<0.001)$ and POS $(\mathrm{r}=-0.51, p<0.001)$. Emotional labor was negatively correlated with PHS $(\mathrm{r}=-0.42, p<0.001)$ and POS $(\mathrm{r}=-0.41, p<0.001)$. PHS was positively correlated with POS ( $\mathrm{r}=0.38, p<0.001)$ (Table 3$)$.

Table 3. Correlation among emotional labor, perceived health status, perceived organizational support and burnout.

\begin{tabular}{|c|c|c|c|c|}
\hline \multirow{2}{*}{ Variables } & Emotional Labor & Perceived Health Status & Perceived Organizational Support & Burnout \\
\hline & $\mathbf{r}(p)$ & $\mathbf{r}(p)$ & $\mathbf{r}(p)$ & $\mathbf{r}(p)$ \\
\hline Emotional labor & 1 & & & \\
\hline Perceived health status & $-0.42(<0.001)$ & 1 & & \\
\hline Perceived organizational support & $-0.41(<0.001)$ & $0.38(<0.001)$ & 1 & \\
\hline Burnout & $0.64(<0.001)$ & $-0.51(<0.001)$ & $-0.51(<0.001)$ & 1 \\
\hline
\end{tabular}

\subsection{Mediating Effects of PHS and POS in the Association between Emotional Labor and Burnout}

Before analyzing the mediating effects of PHS and POS in the association between emotional labor and burnout in PHNs, multicollinearity between independent variables was checked. It was determined that there is no multicollinearity between independent variables based on tolerance $\geq 0.1(0.75-0.78)$, variance inflation factor $(\mathrm{VIF})<10(1.29-1.33)$, and correlation coefficient $<0.80(0.38-0.64)$. Moreover, the Durbin-Watson value was close to 2.00 with 1.75 , indicating no problem with the autocorrelation of errors. With respect to the suitability of the regression model for burnout, Kolmogorov-Smirnov residual normality test results showed $Z=0.05$ and $p=0.200(>0.05)$ to satisfy the assumption of residual normality, while Breusch-Pagan homoscedasticity test results showed $p=1.000$ $(>0.05)$ to satisfy the assumption of homoscedasticity, which confirmed the suitability of the regression model.

The parallel multiple mediator model was analyzed using Process macro V.3.3, which is capable of simultaneously testing both direct and mediating effects using regression analysis. The independent variable emotional labor had a significant effect on mediating variables PHS $(\mathrm{B}=-0.17, p<0.001)$ and POS $(\mathrm{B}=-0.53, p<0.001)$, while the independent variable emotional labor $(\mathrm{B}=1.07, p<0.001)$ and mediating variables PHS $(\mathrm{B}=-1.36$, $p<0.001)$ and POS $(\mathrm{B}=-0.42, p=0.001)$ all had a significant effect on the dependent variable burnout.

The direct effect size of emotional labor on burnout was 1.07, and the results were significant since $95 \%$ bootstrap CI did not include 0 (0.81-1.33). The indirect effect size of emotional labor on burnout mediated by PHS was 0.24 ; the results were statistically significant since $95 \%$ bootstrap CI did not include $0(0.11-0.39)$, while the indirect effect 
size of emotional labor on burnout mediated by POS was 0.23 . The results were significant since $95 \%$ bootstrap CI did not include 0 (0.07-0.42). The sum of indirect effects was 0.46 , and the results were significant since $95 \%$ bootstrap CI did not include 0 (0.29-0.68). These results indicated that higher emotional labor perceived by PHNs could reduce PHS and POS to increase burnout (Table 4, Figure 1).

Table 4. Effects of public health nurses' emotional labor and burnout: The mediating effects of perceived health status and perceived organizational support.

\begin{tabular}{|c|c|c|c|c|c|c|c|c|}
\hline Variables & B & SE & $\mathbf{t}$ & $p$ & \multicolumn{4}{|c|}{$95 \% \mathrm{CI}$} \\
\hline Emotional labor $\rightarrow$ Perceived health status & -0.17 & 0.03 & -6.63 & $<0.001$ & \multicolumn{4}{|c|}{$-0.23 \sim-0.12$} \\
\hline $\begin{array}{l}\text { Emotional labor } \rightarrow \text { Perceived } \\
\text { organizational support }\end{array}$ & -0.53 & 0.08 & -6.49 & $<0.001$ & \multicolumn{4}{|c|}{$-0.69 \sim 0.37$} \\
\hline Emotional labor $\rightarrow$ Burnout & 1.07 & 0.13 & 8.03 & $<0.001$ & \multicolumn{4}{|c|}{$0.81 \sim 1.33$} \\
\hline Perceived health status $\rightarrow$ Burnout & -1.36 & 0.32 & -4.31 & $<0.001$ & \multicolumn{4}{|c|}{$-1.99 \sim-0.74$} \\
\hline $\begin{array}{l}\text { Perceived organizational } \\
\text { support } \rightarrow \text { Burnout }\end{array}$ & -0.42 & 0.10 & -4.18 & $<0.001$ & \multicolumn{4}{|c|}{$-0.62 \sim-0.22$} \\
\hline \multirow{3}{*}{ Variables } & \multicolumn{4}{|c|}{ Directing effect } & \multicolumn{4}{|c|}{ Indirect effect } \\
\hline & \multirow{2}{*}{ B } & \multirow{2}{*}{ Boot SE } & \multicolumn{2}{|c|}{$95 \%$ CI } & \multirow{2}{*}{ B } & \multirow{2}{*}{ Boot SE } & \multicolumn{2}{|c|}{$95 \%$ CI } \\
\hline & & & Boot LLCI & Boot ULCI & & & Boot LLCI & Boot ULCI \\
\hline Emotional labor $\rightarrow$ Burnout & 1.07 & 0.13 & 0.81 & 1.33 & & & & \\
\hline $\begin{array}{l}\text { Emotional labor } \\
\rightarrow \text { Perceived health status } \rightarrow \text { Burnout }\end{array}$ & & & & & 0.24 & 0.07 & 0.11 & 0.39 \\
\hline $\begin{array}{l}\text { Emotional labor } \rightarrow \text { Perceived } \\
\text { organizational support } \rightarrow \text { Burnout }\end{array}$ & & & & & 0.23 & 0.09 & 0.07 & 0.42 \\
\hline Total & & & & & 0.46 & 0.10 & 0.29 & 0.68 \\
\hline
\end{tabular}

$\mathrm{CI}=$ confidential interval.
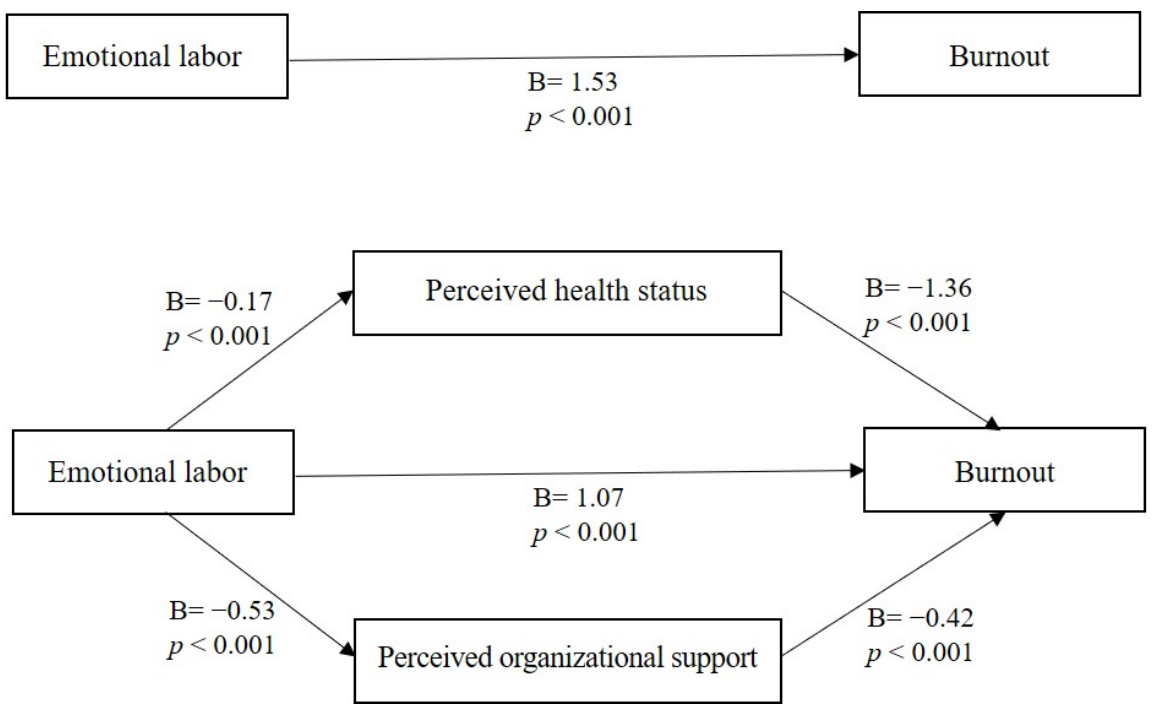

Figure 1. Multiple mediation bootstrap analysis of relationships between emotional labor and burnout as mediated by perceived health status and perceived organizational support.

\section{Discussion}

This study aimed to present basic data for developing an intervention for reducing or preventing burnout due to emotional labor by identifying the level of psychological burden and investigating the mediating effect of PHS and POS in the associations between emotional labor and burnout in PHNs during the ongoing COVID-19 pandemic.

The findings in the study showed that "being stricter on one's self than as required by the government with respect to social distancing and restrictions on personal life" was the highest among the psychological burdens experienced by PHNs, followed in order by "Overload of various work assigned additionally because of being a nurse" and "social 
expectations about sacrifice as a public servant and expectation of kind response." While the direct comparison is difficult due to the lack of previous studies on PHNs, the findings were consistent with a Q-methodology study on public hospital nurses in Korea [33], which reported that nurses experienced psychological stress due to restrictions on the private life of not only themselves but also their family, fear of social stigma when exposed to infection, and excessive workload. Another study on public hospital nurses in Turkey [34] reported that nurses experienced psychological difficulties due to self-imposed restrictions on social activities, loneliness, occupational role conflict, and organizational expectation for crisis management.

During the COVID-19 pandemic, PHNs were initially mobilized for infection control and quarantine, while actively adapting to constantly changing policies and guidelines. They felt pressure from still being responsible for the regular role of providing health promotion and public health services, such as smoking cessation education and vaccination [1] while facing additional COVID-19-related work [35]. In this study, over 50\% of PHNs had a heavy work burden, having performed $\geq 4 \mathrm{~h}$ of COVID-19-related work (50.7\%), $\geq 2 \mathrm{~h}$ of complaint response work $(63.8 \%)$, and $\geq 2$ h of overtime work (59.9\%) in the past one week. Based on such findings, it was determined that under the COVID-19 pandemic, PHNs felt burden from social responsibilities and obligations and role expectations from the community and organization; because nurses are also public servants, their sense of responsibility was doubled. Moreover, they were being overburdened due to the addition of COVID-19-related work, in addition to their regular work.

The first finding in this study showed that higher emotional labor perceived by PHNs directly increased burnout. Various previous studies have already reported the negative effect of emotional labor on burnout among nurses $[15,19,36]$. In a qualitative study on nurses by Lee and Lee [8], nurses struggled with professional responsibilities despite mounting fatigue and added workload due to the non-ending pandemic, but they felt emotional burnout from dealing with non-cooperative patients who repeatedly violate infection control rules, which supported the findings in this study. In a previous study, emotional labor in the domain of "emotional dissonance and hurt" had most effect on burnout [37] and PHNs may experience emotional hurt due to emotional dissonance when they repeatedly show only the emotions demanded by the organization for successful complaint response while suppressing their own emotions. Meier et al. [38] mentioned that senior managers, organizations, and outsiders tend to think that "suppressing one's own emotions and expressing the emotions the organization wants even in situations with increased emotional labor is the price of labor for civil servants," which suggested that response to emotional labor may be slow among civil servants. Therefore, it is necessary to recognize one's own emotions and learn effective emotional management and proper emotional expression methods to manage injury caused by emotional labor.

The second finding in this study showed that PHS has a partial mediating effect on the association between emotional labor and burnout in PHNs. In previous studies, the excessive emotional labor of health care professionals was reportedly associated with physical and mental health problems, such as somatic symptoms [39], depression, hypertension, and heart disease [18]; deterioration of health, such as persistent fatigue, gastrointestinal problem, cardiovascular disorder, and diabetes, could be predictors of burnout among office workers [12]. Moreover, other studies reported that lower subjective health status among PHNs is associated with a higher perceived level of burnout [14]; health care professionals with health problems are more vulnerable to personal and work-related burnout [5]. Such results suggested that long-term accumulation of emotional labor can cause deterioration of personal health [10] to cause an increase in burnout.

The results in this study showed that higher emotional labor in PHNs is associated with a decrease in PHS, which leads to an increase in burnout. It suggests that burnout could be relieved by positively responding to the negative effect of emotional labor if the PHS of PHNs can be enhanced. This study surveyed the PHS of PHNs. However, mental stress may manifest as physical symptoms before it is perceived [40]; thus, PHNs 
must consistently put forth the efforts for early response and continued self-health care once abnormal health symptoms are perceived. Organizations need to put forth efforts to establish a mutually supportive network within public health centers to create an open and healthy workplace culture.

The third finding in this study showed that POS has a partial mediating effect on the association between emotional labor and burnout in PHNs. In other words, higher emotional labor is associated with a decrease in POS, which is in turn associated an increase in burnout. Previous studies reported a negative association between emotional labor and POS among nurses [21] and that when nurses perceived that the organization lacked consideration for the importance of employees and their well-being, there was a decrease in their professional self-concept [11], job commitment, and job satisfaction [24,25]. In contrast, the perception of a pleasant working environment and a sense of receiving organizational care could reduce work-related burnout [28]. These results supported the findings in this study. In a study that included nurses and midwives, more surface acting due to emotional labor was associated with a decrease in POS, which led to decreased job satisfaction [25]. Lartery et al. [25] reported that positive organizational resources could act as a protective factor against the negative consequences of these emotional requirements.

Labrague and de los Santos [41] reported that higher POS among nurses is associated with lower COVID-19-related anxiety while proposing that appropriate organizational support (e.g., structural support, effective communication, safe working environment, COVID-19-related education, and well-being monitoring) is essential for supporting nurses who are directly facing difficulties due to the COVID-19 crisis.

The findings in this study suggested that PHNs need organizational support that they can empathize with when managing emotional labor during their work, which could help alleviate burnout. When PHNs perceive that their own organization will provide even more support, their own emotional regulations could have a positive effect on the prevention of burnout [28]. The Korean government and health authorities were lauded for having an effective disease control by supporting a "K-Quarantine Model" with support of public health personnel and resources, the establishment of an online healthcare system, testing-contact tracing-quarantine through campaigns, and treatments to prevent the spread of COVID-19 in the early stage of the pandemic [42]. However, stable and systematic support has not been easy due to the ongoing pandemic trend, vaccine supply and demand, vaccination, sporadic nationwide outbreaks, and virus mutation. Nonetheless, the roles of PHNs are expected to expand even more since the COVID-19 pandemic is still ongoing, and time has come to implement policies for "with COVID"; thus, organizational and government support for improving working conditions is essential and urgently needed.

These findings determined that higher emotional labor perceived by PHNs could lead to a decrease in PHS and POS, which is associated with an increase in burnout. This suggested that when PHNs experience high emotional labor, increasing PHS and strengthening POS could help alleviate burnout. Interventions that provide effective emotional regulation management education, communication, and psychological counseling support [43] to positively manage the negative effects of emotional labor and maintain fitness and health by recommending meditation, yoga, or exercise [44] could help reduce or prevent PHNs' burnout. Moreover, managers and organizations where the PHNs belong should analyze the COVID-19-related burden, role change, and work scope to provide organizational support, such as adequate rest, flexible work hours, work allocation, and appropriate personnel management, to alleviate burnout [9].

This study had some limitations. Firstly, there are limitations in generalizing the findings since the study population consisted of PHNs from just one region in Korea. Secondly, because health status was identified based on subjective health status perceived by PHNs, it is necessary to check the actual physical health problems. Thirdly, this study did not consider actual organizational support, such as pay, benefits, and working environment. Future studies should investigate organizational support for PHNs during the COVID-19 pandemic and its outcomes. Fourthly, because the psychological burden was surveyed with 
a single question, there are limitations in interpreting the results; the causal relationship with emotional labor or burnout could not be identified. There is a need to conduct in-depth qualitative studies on the effects on psychological burden and burnout with consideration for the job characteristics of PHNs. Moreover, this study did not identify the mediating effects of work engagement [45], stress [39], and job satisfaction [16], which could affect the association between emotional labor and burnout in PHNs.

Because PHS and POS, in relation to emotional labor and burnout, were investigated by a cross-sectional survey, there are limitations in generalizing the findings; in the future, there is a need for longitudinal design studies on the accumulation of fatigue in PHNs and identification of outcomes regarding burnout due to the continuation of the pandemic.

This study has limitations in generalizing the results because convenience sampling was used to obtain participants. Despite these limitations, this study was significant in that it presented measures for reducing burnout in PHNs by testing the mediating effects of PHS and POS in the association between emotional labor and burnout in PHNs responsible for providing public health services during the COVID-19 pandemic.

\section{Conclusions}

This study analyzed the mediating effects of PHS and POS in how the emotional labor of PHNs affect burnout to provide basic data for the development of burnout prevention programs for nurses who play a central role in public healthcare service, while also presenting the need for interventions at personal and organizational levels. It presented evidence that when emotional labor is high, increasing PHS and strengthening POS could help reduce burnout.

Based on these findings, it is believed, to reduce burnout among PHNs, it is necessary to develop and operate burnout prevention programs to increase PHS and strengthen organizational support while also reducing emotional labor through physical activities and emotional regulation. Future studies are recommended for investigating work-related burnout among PHNs and physical and emotional mediating or regulating variables that may have changed after the COVID-19 pandemic.

Author Contributions: Conceptualization, M.-N.K., Y.-S.Y., O.-H.C. and K.-H.H.; methodology, M.-N.K., Y.-S.Y. and O.-H.C.; software, M.-N.K. and O.-H.C.; validation, M.-N.K. and Y.-S.Y.; formal analysis, Y.-S.Y.; investigation, M.-N.K.; resources, O.-H.C.; data curation, O.-H.C. and K.-H.H.; writing-original draft preparation, M.-N.K., O.-H.C. and K.-H.H.; writing-review and editing, M.-N.K., Y.-S.Y., O.-H.C. and K.-H.H.; visualization, K.-H.H.; supervision, M.-N.K.; project administration, Y.-S.Y. All authors have read and agreed to the published version of the manuscript.

Funding: This research received no external funding.

Institutional Review Board Statement: This study was conducted according to the guidelines of the Declaration of Helsinki and approved by the Institutional Review Board of Kongju National University (IRB No: KNU_IRB_2021-05).

Informed Consent Statement: Written informed consent has been obtained from the patients to publish this paper.

Data Availability Statement: Data are available upon request.

Acknowledgments: We give thanks to the public health nurses who participated in the study.

Conflicts of Interest: The authors declare no conflict of interest.

\section{References}

1. Drevdahl, D.J.; Canales, M.K. Being a real nurse: A secondary qualitative analysis of how public health nurses rework their work identities. Nurs. Inq. 2020, 27, e12360. [CrossRef]

2. Hayes, C.; Corrie, I.; Graham, Y. Paramedic emotional labour during COVID-19. J. Paramed. Pract. 2020, 12, 319-323. [CrossRef]

3. Zhao, H.; He, Y.; Brister, F.; Yang, L.; Li, G.; Ling, Y.; Ying, Y. How Can Nursing Teams Respond to Large-Scale COVID-19 Screening? Front. Public Health 2021, 9, 681255. [CrossRef] 
4. Edmonds, J.K.; Kneipp, S.M.; Campbell, L. A call to action for public health nurses during the COVID-19 pandemic. Public Health Nurs. 2020, 37, 323-324. [CrossRef]

5. Duarte, I.; Teixeira, A.; Castro, L.; Marina, S.; Ribeiro, C.; Jácome, C.; Martins, V.; Ribeiro-Vaz, I.; Pinheiro, H.C.; Silva, A.R.; et al Burnout among Portuguese healthcare workers during the COVID-19 pandemic. BMC Public Health 2020, 20, 1885. [CrossRef]

6. Stone, K.; Kintziger, K.; Jagger, M.; Horney, J. Public Health Workforce Burnout in the COVID-19 Response in the U.S. Int. J. Environ. Res. Public Health 2021, 18, 4369. [CrossRef]

7. Hankyoreh News. Nurses at Public Health Centers after 'Quarantine Burnout' Increased by 1.5 Times. Available online: https://www.hani.co.kr/arti/society/health/1004767.html (accessed on 28 July 2021).

8. Lee, N.; Lee, H.-J. South Korean Nurses' Experiences with Patient Care at a COVID-19-Designated Hospital: Growth after the Frontline Battle against an Infectious Disease Pandemic. Int. J. Environ. Res. Public Health 2020, 17, 9015. [CrossRef]

9. Morgantini, L.A.; Naha, U.; Wang, H.; Francavilla, S.; Acar, Ö.; Flores, J.M.; Crivellaro, S.; Moreira, D.; Abern, M.; Eklund, M.; et al. Factors contributing to healthcare professional burnout during the COVID-19 pandemic: A rapid turnaround global survey. PLOS ONE 2020, 15, e0238217. [CrossRef]

10. Aung, N.; Tewogbola, P. The impact of emotional labour on the health in the workplace: A narrative review of literature from 2013-2018. AIMS Public Health 2019, 6, 268-275. [CrossRef]

11. Cao, X.; Chen, L.; Tian, L.; Diao, Y. The effect of perceived organisational support on burnout among community health nurses in China: The mediating role of professional self-concept. J. Nurs. Manag. 2015, 24, E77-E86. [CrossRef]

12. Salvagioni, D.A.J.; Melanda, F.N.; Mesas, A.E.; González, A.D.; Gabani, F.L.; De Andrade, S.M. Physical, psychological and occupational consequences of job burnout: A systematic review of prospective studies. PLoS ONE 2017, 12, e0185781. [CrossRef]

13. Søvold, L.E.; Naslund, J.A.; Kousoulis, A.A.; Saxena, S.; Qoronfleh, M.W.; Grobler, C.; Münter, L. Prioritizing the Mental Health and Well-Being of Healthcare Workers: An Urgent Global Public Health Priority. Front. Public Health 2021, 9, 679397. [CrossRef]

14. Hanafin, S.; Cosgrove, J.; Hanafin, P.; Brady, A.-M.; Lynch, C. Burnout and its prevalence among public health nurses in Ireland. Br. J. Community Nurs. 2020, 25, 370-375. [CrossRef]

15. Zaghini, F.; Biagioli, V.; Proietti, M.; Badolamenti, S.; Fiorini, J.; Sili, A. The role of occupational stress in the association between emotional labor and burnout in nurses: A cross-sectional study. Appl. Nurs. Res. 2020, 54, 151277. [CrossRef]

16. Cho, K.S.; Kim, Y. Emotional Labor, Job Stress and Professional Quality of Life of Public Health Nurses according to the Employment Type. J. Korean Acad. Nurs. Adm. 2019, 25, 467-477. [CrossRef]

17. Rose, S.; Hartnett, J.; Pillai, S. Healthcare worker's emotions, perceived stressors and coping mechanisms during the COVID-19 pandemic. PLoS ONE 2021, 16, e0254252. [CrossRef]

18. Kumar, S.; Shankar, B.; Singh, A.S.P. Emotional labor and health outcomes: An overview of literature and preliminary empirical evidences. Indian J. Soc. Sci. Res. 2010, 7, 83-89.

19. Soto-Rubio, A.; Giménez-Espert, M.; Prado-Gascó, V. Effect of Emotional Intelligence and Psychosocial Risks on Burnout, Job Satisfaction, and Nurses' Health during the COVID-19 Pandemic. Int. J. Environ. Res. Public Health 2020, 17, 7998. [CrossRef]

20. Yeh, S.C.J.; Chen, S.H.S.; Yuan, K.S.; Chou, W.; Wan, T.T.H. Emotional labor in health care: The moderating roles of per-sonality and the mediating role of sleep on job performance and satisfaction. Front. Psychol. 2020, 11, 574898. [CrossRef]

21. Bukhari, S.R.; Alam, N.A.; Batool, A.; Hussain, Y.; Asim, S.; Khatttak, N.; Tabassum, S. Perceived Organizational Support Predicts Emotional Labor Among Nurses. Asian Soc. Sci. 2020, 16, 68. [CrossRef]

22. Eisenberger, R.; Huntington, R. Perceived organizational support. J. Appl. Psychol. 1986, 71, 500-507. [CrossRef]

23. Rhoades, L.; Eisenberger, R. Perceived organizational support: A review of the literature. J. Appl. Psychol. 2002, 87, 698-714. [CrossRef]

24. Choi, Y. Perceived Organizational Support and Organizational Commitment in Hospital Nurses: Mediating and Moderating Effect of Resilience. Master's Thesis, Yonsei University, Seoul, Korea, 2015.

25. Lartey, J.K.S.; Amponsah-Tawiah, K.; Osafo, J. The moderating effect of perceived organizational support in the relationship between emotional labour and job attitudes: A study among health professionals. Nurs. Open 2019, 6, 990-997. [CrossRef]

26. Kim, J. Emotional Labor Strategies, Stress, and Burnout among Hospital Nurses: A Path Analysis. J. Nurs. Sch. 2019, 52, 105-112. [CrossRef]

27. Bobbio, A.; Bellan, M.; Manganelli, A.M. Empowering leadership, perceived organizational support, trust, and job burnout for nurses. Health Care Manag. Rev. 2012, 37, 77-87. [CrossRef]

28. Grama, B.G.; Balas, M. Organizational support, emotional labor and burnout regarding the medical staff. Acta Med. Transilv. 2018, 23, 16-19.

29. Pines, A.M.; Aronson, E.; Kafry, D. Burnout: From Tedium to Personal Growth; A Division of Macmilian Publishing Co., Inc.: New York, NY, USA, 1981.

30. Morris, J.A.; Feldman, D.C. The Dimensions, Antecedents, and Consequences of Emotional Labor. Acad. Manag. Rev. 1996, 21, 986-1010. [CrossRef]

31. Speake, D.L.; Cowart, M.E.; Pellet, K. Health perceptions and lifestyles of the elderly. Res. Nurs. Health 1989, 12, 93-100. [CrossRef]

32. Hayes, A.F. Introduction to Mediation, Moderation, and Conditional Process Analysis: Regression-Based Approach; Lee, H.K., Ed.; Guilford Press: New York, NY, USA, 2013.

33. Cho, K.; Kim, B. The Psychological Responses of Nurses Caring for COVID-19 Patients: A Q Methodological Approach. Int. J. Environ. Res. Public Health 2021, 18, 3605. [CrossRef] 
34. Muz, G.; Yüce, G.E. Experiences of nurses caring for patients with COVID-19 in Turkey: A phenomenological enquiry. J. Nurs. Manag. 2021, 29, 1026-1035. [CrossRef]

35. Dowell, J. What's It Like Being a Public Health Nurse during the Pandemic? Available online: https://www.samuelmerritt.edu/ news / whats-it-being-public-health-nurse-during-pandemic (accessed on 30 July 2021).

36. Deng, H.; Wu, H.; Qi, X.; Jin, C.; Li, J. Stress Reactivity Influences the Relationship between Emotional Labor Strategies and Job Burnouts among Chinese Hospital Nurses. Neural Plast. 2020, 2020, 8837024. [CrossRef]

37. Choi, H.; Ha, Y.; Yang, S. Relationships among emotional lab or, self-efficacy and burnout of employees in public health centers. Korean J. Occup Health Nurs. 2016, 25, 75-82. [CrossRef]

38. Meier, K.J.; Mastracci, S.H.; Wilson, K. Gender and Emotional Labor in Public Organizations: An Empirical Examination of the Link to Performance. Public Adm. Rev. 2006, 66, 899-909. [CrossRef]

39. Oh, Y.J.; Choi, Y.H. Effects of emotional labor, job stress and burnout on somatization in nurses: In convergence era. J. Digit. Converg. 2015, 13, 415-424. [CrossRef]

40. Sohn, B.K.; Park, S.M.; Park, I.-J.; Hwang, J.Y.; Choi, J.-S.; Lee, J.-Y.; Jung, H.-Y. The Relationship between Emotional Labor and Job Stress among Hospital Workers. J. Korean Med. Sci. 2018, 33, e246. [CrossRef]

41. Labrague, L.J.; de Los Santos, J.A.A. COVID-19 anxiety among front-line nurses: Predictive role of organisational support, personal resilience and social support. J. Nurs. Manag. 2020, 28, 1653-1661. Available online: https:/ / onlinelibrary.wiley.com/ doi/abs/10.1111/jonm.13121 (accessed on 8 July 2021). [CrossRef]

42. Kang, J.; Jang, Y.Y.; Kim, J.; Han, S.-H.; Lee, K.R.; Kim, M.; Eom, J.S. South Korea's responses to stop the COVID-19 pandemic. Am. J. Infect. Control 2020, 48, 1080-1086. [CrossRef]

43. Burton, J. WHO Healthy Workplace Framework and Model: Background and Supportive Literature and Practices; World Health Organization: Geneva, Switzerland, 2010; Available online: https://www.who.int/occupational_health/healthy_workplace_framework. pdf (accessed on 28 July 2021).

44. Latino, F.; Cataldi, S.; Fischetti, F. Effects of an 8-Week Yoga-Based Physical Exercise Intervention on Teachers' Burnout. Sustainability 2021, 13, 2104. [CrossRef]

45. Han, S.-S.; Han, J.-W.; Kim, Y.-H. Effect of Nurses' Emotional Labor on Customer Orientation and Service Delivery: The Mediating Effects of Work Engagement and Burnout. Saf. Health Work 2018, 9, 441-446. [CrossRef] 